\title{
The Stagnancy of Family Studies in Modern Academia: Resistances Toward the Integration of Evolutionary Theory
}

\author{
Ashley C. King • Tomas Cabeza de Baca
}

Published online: 22 January 2011

(C) Springer Science+Business Media, LLC 2011

\begin{abstract}
The theory of natural selection has been vital in unifying the biological sciences and their research with a single testable metatheory. Despite a plethora of research supporting natural selection, teaching the theory of evolution remains controversial in high schools and higher education (Wilson et al. 2009; Scott 1997). In this article, we sample the attitudes toward evolution of 170 faculty and graduate and undergraduate students in family studies and human development programs from across the United States to determine whether resistances toward evolution remain and to describe the correlates of these resistances. Results reveal that an individual's prosocial meliorist attitudes, religious ideation, and his or her reported interest in and knowledge of evolution all uniquely contribute to whether they report evolutionary theory as being applicable to their area of research interests. We discuss the relevance of including evolutionary theory within family studies and human development research programs and make suggestions for how to implement an evolutionary studies program (Wilson et al. 2009).
\end{abstract}

Keywords Teaching evolution · Human development and family studies $\cdot$ Resistances toward evolution

Evolution by natural selection has been a major unifying theory throughout the biological sciences, linking various disciplines with a single testable idea; however, despite years of empirical evidence, the teaching of natural selection and evolution remains controversial and resisted

The authors would like to acknowledge and thank Dr. A. J. Figueredo for his insightful and helpful comments on an early version of this manuscript.

A. C. King $(\bowtie) \cdot$ T. C. de Baca

University of Arizona

Tucson, AZ, USA

e-mail: aking1@email.arizona.edu by many, influencing teaching curricula in high schools and higher education (Wilson et al. 2009; Scott 1997). As a result, despite evolution's broad applicability, many people in the social sciences neglect to see its relevance to their areas of study, thus causing what can sometimes be detrimental effects (Wilson 2007; Geher and Gambacorta 2010).

Family studies and human development (also referred to as human development and family studies or school of family and developmental studies), is a common department found across the United States in over 150 college and university systems (College Board 2010). Although evolution is most certainly applicable to any research program which seeks to explain human development or family functioning, most research in these areas remains agnostic about evolution. At best, introductory text books may make reference to evolutionary processes, but little time is spent discussing the theoretical implications of evolution and in explaining its applicability to the study of human development (Sigelman et al. 2009). Instead, research in these fields is segmented, with some researchers using Piaget's (1930) stage theory as a guiding framework, others employing John Bowlby's attachment theory (1951, 1973), and still others conducting research from a feminist perspective (Fox and Murry 2000; Erickson 2005).

One area of research which can clearly demonstrate the impact of neglecting to use an evolutionary perspective is that of risky adolescent behavior. Work in this area typically employs a traditional mental health model view, popularized by Freud in the 1930s. This model views any deviations from "normal" development as a disorder, requiring public policy programs and interventions for early prevention (Dahl 2004); however, an evolutionarily informed perspective views risky adolescent behavior through a very different lens. Life history theorists, for example, operate under a broader evolutionary framework. Recently, researchers have pre- 
sented an adaptive calibration model, which seeks to explain why individuals may engage in a suite of risky adolescent behaviors because they serve some adaptive purpose or function (DelGiudice et al. 2010). From this perspective, adolescent males may engage in a variety of risky sensation-seeking behaviors not due to pathology, but because these behaviors are often sought after by females, thus improving a male's reproductive potential and rendering the behaviors a form of mating effort which has proven successful in the past (DelGiudice et al. 2010).

Another area of study popular in family studies and human development departments revolves around child growth and developmental functioning. Humans' delayed period of physical and cognitive immaturity is quite costlyboth for parents and offspring. Because evolution favored an extended childhood in spite of the added costs of care, protection from predation, additional food acquisition, and more, researchers have argued that the long period of dependency must have served some adaptive purposes (King et al. 2010; Geary and Bjorklund 2000). For example, this time could be used for children to develop socially, physically, and cognitively, so they are better prepared for adulthood. In line with this, King and Bjorklund (2010) have argued that some aspects of immature childhood cognition can actually be adaptive. For example, children have a poor ability to judge their own competency relative to their peers in a variety of tasks, often overestimating their own abilities. Bjorklund (2007) has shown that this overestimation can be beneficial because it encourages children to attempt a wide range of activities and to learn from their performance, rather than considering it a failure. These adaptive limitations may actually function to increase a child's learning potential throughout development (Bjorklund 2007). Although many mainstream programs exist that try to foster early reading or speaking abilities in young children, an evolutionarily informed perspective allows researchers to recognize the adaptive benefits of slow maturation and cautions us to "provide children with intellectual experiences tailored to their capabilities, rather than trying to endow them with skills ill suited for their biologically determined cognitive systems" (Bjorklund and Green 1992, p. 52).

In spite of the benefits of conducting research in family studies and human development from an evolutionarily informed perspective, several resistances to its integration remain. There are many reasons for these resistances, and in this paper, we will attempt to outline and explain various obstacles to the teaching of evolution and to explicate the reasons why evolution is so often absent from research coming out of family studies programs. By surveying faculty and students affiliated with these programs, we will be able to empirically assess correlates of this resistance and to propose ways to address and overcome common obstacles by implementing basic pedagogical programs first proposed by Wilson et al. (2009) that are designed to benefit individuals at all stages of higher education, from tenured faculty to undergraduates. Discussing the concept of evolution across a broad array of disciplines can create more informed thinkers, researchers, and students and has the power to ultimately cause a better integrated and knowledgeable literature through the fostering and development of cross-disciplinary collaborations.

\section{Resistance Toward Evolution}

At an individual level, Hagard and Findlay (2010) theorize that there are three main areas of resistance toward acknowledging natural selection as a mechanism underlying individual variation in human beings. To briefly summarize, resistance to selectionist theories of human evolution occurs due to (1) cognitive difficulties, where individuals have a conceptual difficulty attributing stochastic variation in species, especially humans, to selective forces within the environment and fail to understand the nature of science and evolution; (2) emotional or religious resistance, where individuals experience existential despair and meaninglessness from believing that evolution and natural selection leaves a world devoid of divine reassurances and purpose; and (3) political resistance, where perceived conflicts with certain forms of political conservatism, or in some cases, liberalism, may impede understanding and acceptance of evolution. Additionally, it is theorized that, though evolution in human beings is controversial among non-scientists, assertions of the evolution of the human mind is, according to Hagard and Findlay (2010), a possibly more contentious issue to accept and a key tenet of evolutionary psychology.

\section{Cognitive Impact}

Cognitive difficulties are one of the most basic and primary obstacles to overcome when teaching evolution. There are two main cognitive barriers to teaching evolutionary theory: misinformation, as when a student is misinformed about the workings of natural selection, and lack of information, as when a student is uninformed entirely about evolutionary theory and how it is applicable to their field of study. The former is one of the easiest obstacles to overcome, in that it would require simple pedagogical shifts to ensure that faculty and students, alike, are absorbing and disseminating accurate information based on scientific data. The latter has been much more difficult to address, specifically at the high school level, but even within higher education, as well. 
Some high school biology courses and even many higher-level collegiate courses may omit or downplay the importance of evolution from their curriculum. According to Downie (2004), 63\% of medical schools surveyed in the United Kingdom include no lessons in evolution and its applicability to medicine and humans. Recently, there has also been resurgence from several states within the United States to include teaching "intelligent design theory" sideby-side with evolutionary theory. "There are efforts to discourage the teaching of evolution by requiring teachers to read disclaimers before teaching it, to teach it as 'theory, not fact,' or to present 'evidence against evolution' within their lectures" (Scott 1997, p. 263).

Although rejected by scientists, intelligent design arguments and publications are surfacing at the collegiate level as accurate representations of scientific scholarship (although these books and articles are typically written for a general audience, rather than for scholars or scientific advancement, per se; Scott 1997). If higher education courses - especially those in the social sciences-incorporated evolution into their lessons, evidence supports that students, despite their prior knowledge level of natural selection, may increase acceptance of the theory (Bishop and Anderson 1990).

\section{Religions' Impact}

When contemplating the publication of On the Origin of Species, Darwin was initially quite troubled by the undeniable turmoil it would create within his religious community. His own wife, Emma, was a devout Christian and the heretical nature of Darwin's work at that time would most certainly be met with harsh resistance from the church (Barlow 1958; Darwin 1887). Although speculative, it may be for these reasons that Darwin initially withheld from discussing evolution by natural selection in a human context, although the groundwork was laid and the connection was indisputable. Thus marked the beginning of what has continued to this day to be a resistance to evolutionary theory on a religious basis.

Empirical data testing, Hagard and Findlay's (2010) aforementioned three areas of resistance reveal that certain forms of religiosity may alter teaching behaviors of educators and may be linked with cognitive resistance toward evolution. Among high school biology teachers, religious convictions negatively correlated with acceptance of evolution $(r=-.80)$, presenting and teaching of evolution in the classroom $(r=-.65)$, and understanding of evolution $(r=-.65$; Trani 2004). Based on these findings, it could be that biology teacher's religious convictions are influencing their understanding of evolution and their teaching curriculum by minimizing natural selection within their classrooms.
Similarly, students in higher education may also reject evolution based on their religiosity. Biology and medical students in the United Kingdom cite religion as a reason to reject evolution (Downie and Barron 2000; Downie 2004) with $11 \%$ of students enrolled in medical school rejecting evolution completely and $91 \%$ of those doing so on religious grounds (Downie 2004).

\section{Political Impact}

Despite the United States' separation of church and state, the two remain inextricably tied. Our country was founded by individuals seeking religious freedom (D'Antonio and Hoges 2006), and throughout the years, politics and religion have continued to be intertwined. Indeed, throughout the second half of the twentieth century, conservative Republicans have adopted creationism as part of their political platforms, with seven states in the 1990s explicitly making demands for teaching creationism in school (Miller et al. 2006). Indeed, religious beliefs and political motivations are often closely related and the dichotomy has evolved to be one in which conservatives have been stereotyped as antievolutionist (Richards 2008), while those studying evolution are more likely to identify themselves as liberal (Tybur et al. 2007).

Although reality is more complicated than this simple overgeneralization, it is likely that extremists on each end of the political continuum may be likely to oppose evolution, but for differing reasons. While many fundamentalists deny evolution based on Biblical literalism, the United States has seen a fair share of anti-evolution sentiment from liberal radicals, as well. For example, E. O. Wilson's initial publication of Sociobiology in 1975, which extended evolution by natural selection to human social behavior, caused him to be "picketed and protested not by Biblical literalists, but by activists from the political left who objected not on the basis of traditional religious beliefs but on the basis of what they believed to be its undermining of progressive ideals about racism, sexism, and fascism in general" (Richards 2008, p. 158).

One liberal group that has attacked natural selection is feminist scholars. Evolutionary theory has historically been repudiated by feminists who believe that biology and natural selection are tools to perpetuate "right wing" ideals that emphasize patriarchal rhetoric of female subjugation and that, consequently, have long-term political implications (Gowaty 1992; Wright 1994). Further adding to the "biophobia" of feminists is the accusation that biological explanations may be "genetically deterministic" allowing a justification for "natural" behavior that continues to oppress and control female gender roles and sexuality (Campbell 2002; Wright 1994), despite the fact that sociobiologists 
make no claims of this nature. Rather, the goal of evolutionarily oriented science is to explain why social behaviors exist, not to justify any particular human trait or characteristic (Alcock 2009).

These misunderstandings and misconceptions on the part of feminists are particularly troubling for work in family studies and human development departments, where feminist perspectives are widely taught and respected, and are often cited as the theoretical basis for research studies despite the fact that the perspective is better categorized as a "framework," which lacks the explanatory power of a "true" theory. Although there has been a gradual shift, where some feminists have begun to apply evolution to key developmental and family-oriented issues (see Hrdy 1981; Lancaster 1991), the inclusion of evolutionary tenets is still far from being mainstream among feminists. Although more research is needed to explicate the relation between political affiliation and attitudes toward evolution, it is clear that the former influences the latter and that there continues to be overwhelming resistances toward the use of evolution both by liberals as well as conservatives, especially for those who find themselves on the extremes of the continuum.

\section{Evolution in Family Studies and Human Development}

Resistance to evolution in the social sciences - especially in specific sub-disciplines of psychology-has been attributed toward ignorance of the theory and the tenets of natural selection and historical "abuse" of the theory (Hagen 2005; Perry and Mace 2010). Even at the university level, simply studying social sciences correlates positively with rejection of evolutionary approaches (Perry and Mace 2010). In the developmental sciences specifically, there is a resistance to applying evolutionary theory to key family and developmental research questions that have been obstacles for researchers. Some developmentalists oppose adopting an evolutionary perspective because they view it as genetically driven and deterministic in nature, failing to take into account important environmental variation and its impact on development (King and Bjorklund 2010). Indeed, many developmentalists discount biological influences on development and overestimate the impact of nurture. According to Geher and Gambacorta (2010), faculty in women's studies and sociology, both closely related fields to family studies and human development, are significantly biased toward citing nurture as the primary force in shaping a child's developmental outcomes, relative to the ratings of other academics.

In line with Geher and Gambacorta's (2010) findings, Charlesworth (1992) has argued that developmental science's resistance toward natural selection may lie in the fact that developmentalists are likely to have meliorist ideals.
Meliorism is the idea that humans are mostly good and that efforts to improve the lives of children will be effective (Charlesworth 1992). It is an emotionally rooted personality characteristic that is a commonplace in family studies and human development. For those with meliorist attitudes, theories emphasizing nurture (e.g., attachment theories) are quite attractive, while those that place any emphasis on biological components to development are far less favored (Charlesworth 1992). Because of this ideology, natural selection, to a meliorist, is nothing more than a dim and dismal theory that facilitates little improvement for the extant lives of children and may breed harsh, competitive, and inequitable environments.

The focus of the current paper is to explore whether students and faculty in family studies and human development (FSHD) programs recognize the applicability of evolutionary theory for research programs. We would expect individuals in family studies programs to have many of the resistances we've outlined above, namely the lack of pedagogy dedicated to teaching evolution and integrating it within their department, thus causing uninformed or misinformed graduates of such programs. Additionally, due to their lack of experience with evolutionary theory, we argue that some students may not realize its applicability, instead viewing evolution as not applicable, or even in opposition to their own guiding theoretical framework(s).

In this paper, we explore personality traits of faculty and graduate and undergraduate students in FSHD departments and their attitudes toward evolution. Secondly, we explore whether meliorist personality traits and/or religious or political convictions may be at the heart of family studies and human development programs' decision to include or exclude evolution in empirical studies and in the classroom. Accordingly, based on the survey results, we formulate suggestions for family studies and human development to incorporate evolution into their extant lines of research and curricula, as well as to participate in cross-disciplinary evolutionarily oriented seminars.

\section{Method}

\section{Recruitment and Participants}

Faculty members and graduate students were recruited via public university's family studies and human development departmental websites. Once email addresses were obtained, emails with links to the study were sent to 395 faculty members and 186 graduate students throughout the United States. A two-week follow-up email was sent out to remind participants to fill out the survey. Undergraduate students were recruited via online courses offered through the authors' university. Undergraduate participants were 
offered extra credit in exchange for participation, though no incentives were given for other participants.

A total of 170 people (58 faculty members, 31 graduate students, and 35 undergraduate students) agreed to participate. Participants spanned 21 universities in 18 states in the United States, ranging from Arizona to Idaho, Florida to Pennsylvania, Texas to Wisconsin, and all in between. All participants were asked to complete three questionnaires designed to assess their attitudes toward evolution as well as meliorist personality traits that were hypothesized to correlate negatively with acceptance of evolutionary theory. In addition to these measures, all participants answered a few demographic questions designed to assess the participant's location, their political affiliation, and their status within the department (undergraduate, graduate, faculty, retiree).

\section{Attitudes Toward Evolution}

The attitudes toward evolution questionnaire was created by the authors, in addition to using select items from previously existing scales designed to assess knowledge about evolutionary theory and resistance toward it (Shtulman 2006; Sikkink 2009). The questionnaire includes four subscales measuring broader constructs: interest/knowledge (four items, $\alpha=.589$ ), perceived applicability (four items, $\alpha=.659$ ), religious ideation (four items, $\alpha=.521$ ), and access to evolution (six items, $\alpha=.763$ ). Sample items for each subscale can be found in the Appendix. In addition to the standardized questions presented, participants were also asked a few qualitative questions, so as to best assess participants' research interests and reasons for their absence of utilization of evolutionary theory within their research paradigms.

\section{Personality Assessment}

In order to assess the extent to which participants exhibit meliorist attitudes, the Measure of Understanding, Support, and Helpfulness (MUSH) scale was created for the study. The 32-item MUSH scale was created from composites of other personality scales (Caruso and Mayer 1998; Davis 1980, 1983; Stapel and Koomen 2005) and consists of four subscales that tap into key meliorist constructs (understanding, eight items: $\alpha=.818$; support, seven items: $\alpha=.778$; attitudes of helpfulness, seven items: $\alpha=.606$; and instrumental helpfulness, ten items: $\alpha=.789$ ) and were composited into an overall MUSH score. Attitudes of helpfulness measure an individual's willingness and competency of helpful behaviors and whether they endorse assisting others. Instrumental helpfulness measures actual helping behaviors participants engage in. Sample items for each subscale can be found in the Appendix. Individuals scoring high on MUSH endorsed more prosocial and meliorist attitudes.

\section{Results}

First, we wanted to determine the degree to which these participants value evolutionary theory as a reasonable metatheory that can inform their research programs. To assess this, we looked at the perceived applicability subscale, which measured the extent to which participants endorsed evolutionary theory as being applicable to their area of research. We ran basic descriptive statistics, which supported our hypothesis that overall, participants largely viewed evolutionary theory as not at all applicable (28.2\%) or a little applicable $(39.3 \%)$ rather than viewing it as somewhat $(24.7 \%)$ or a great deal applicable $(7.7 \%)$ to their research.

Next, we wanted to determine the correlates of this lack of perceived applicability that permeated the results of this study. We ran a series of $t$ tests to find whether differences in any of our constructs emerged due to sex. The relation between sex and the interest/knowledge construct was significant with males $(M=3.73, \mathrm{SD}=.81)$, on average, rating themselves as significantly more knowledgeable about and interested in evolution than females $(M=3.29, \mathrm{SD}=.71)$, $t(116)=-2.483, p<.01$. Moreover, females $(M=5.54$, $\mathrm{SD}=.43)$ scored higher on MUSH than males $(M=5.29$, $\mathrm{SD}=.45), t(104)=2.059, p<.04$, meaning females scored higher on meliorist attitudes than males. It is important to note, however, that family studies tend to be a heavily female-dominant population (e.g., 95\% female, 5\% male, Auburn University Enrollment Statistics 2010; 88\% female, $12 \%$ male, K. Weaver, personal communication, November $19,2010)$, and our sample reflects this sex bias ( $82 \%$ female respondents, $18 \%$ male respondents).

We then ran bivariate correlations between other variables of interest. Age was significantly correlated with interest $/$ knowledge, $r=.256, p=.005$, with older participants expressing an increasing amount of interest in and knowledge of evolutionary theory, as we would expect. Interestingly, age significantly correlated negatively with religious ideation, $r=-.318, p=.001$, such that older participants were less likely to report religious beliefs as barriers to their utilization of evolutionary theory. Because of the nature of correlational research, we cannot tease apart whether these relations are due specifically to age, to academic position (which also significantly correlated with age, $r=.851, p<.001$ ), or to some combination of both.

Analyses of age on components of the MUSH scale revealed significant age-related correlations. Attitudes of helpfulness increased with age, $r=.408, p<.001$; however, reports of instrumental helpfulness decreased as the 
participants became older, $r=-.191, p<.043$. Correlations imply that though participants report having more prosocial attitudes towards helping others as they become older, actual reports of helping others decreases. Further analyses on academic position and meliorist attitudes revealed a significant correlation, $r=.330, p<.001$, where faculty members endorsed higher meliorist attitudes on the MUSH scale. Interestingly, and perhaps a product of age, higher faculty position correlated with higher attitudes of helping, $r=.516, p<.001$, but, as we saw with age, less instrumental helpfulness, $r=-.204, p<.030$. Testing the MUSH scale's validity, MUSH positively correlated with agreeableness $(r=.331, p<.001)$ and conscientiousness $(r=.244, p<.013)$, meaning that MUSH is accurately assessing prosocial and meliorist attitudes in participants.

\section{Attitudes Toward Evolution}

We had hypothesized that extreme religious or political ideations could serve as potential barriers to the acceptance of evolutionary theory and its applicability within family studies programs of research. Interestingly, our hypotheses were not supported, but rather we found that those who claimed to be highly religious were also those who reported evolution as being more applicable to their field of research $r=384, p<.001$. Also counter to our hypothesis, political identity had a significant negative correlation with perceived applicability, $r=-.278, p=.002$. As shown in Table 1 , those who selfidentified as "extreme liberals" reported evolutionary theory as least applicable, and those self-identified as "moderate conservatives" (no one from this sample self-identified as "extreme conservative") were most likely to condone evolutions' applicability; however, it should again be noted that overall, participants overwhelmingly reported that they did not view evolutionary theory as applicable to their research interests.

Interest/knowledge significantly correlated with applicability, $r=.338, p<.001$, such that people more knowledgeable about and interested in evolutionary theory also found it more applicable to their studies. Additionally, we found a

Table 1 Perceived applicability of evolutionary theory by political affiliation

\begin{tabular}{lccc}
\hline & Mean & $N$ & SD \\
\hline Moderate conservative Republican & 2.99 & 20 & .909 \\
Changing affiliation/no affiliation & 2.66 & 11 & 1.17 \\
Moderate liberal Democrat & 2.41 & 56 & .729 \\
Extreme liberal Democrat & 2.25 & 30 & .963 \\
\hline
\end{tabular}

Participants who self-identified as "extreme liberals" reported evolutionary theory as least applicable to their area of research, while those who self-identified as "moderate conservatives" rated evolutionary theory as most applicable to their research interests. No one from this sample self-identified as an "extreme conservative" significant negative correlation between religious ideation and interest/knowledge, $r=-.236, p=.011$, such that those who endorsed stronger religious beliefs were less interested in and knowledgeable about evolutionary theory. Additionally, those who found evolutionary theory applicable to their research areas were likely to report it as being accessible within their department, $r=.272, p=.004$. This could be due to self-selection (those interested in studying from an evolutionary perspective seek out university systems that are more accommodating and accessible for this type of study), or it could be that those uninterested or uninformed about evolutionary theory are unaware of its accessibility within their university system.

A series of linear regressions were run to ascertain whether differences in participants' meliorist attitudes and religious beliefs uniquely contributed to the variance in their selfreported degree of applicability of evolutionary theory. As shown in Table 2, access to evolution $(B=.199, p=.03)$, religious ideation $(B=.454, p<.001)$, interest $/$ knowledge $(B=.278, p=.004)$, and MUSH $(B=-.233, p=.007)$ all uniquely contributed to the variance in participants' perceptions of the applicability of evolutionary theory to their research. This means that an individual's religious proclivities, meliorist attitudes, and reported interest in and knowledge of evolution all uniquely contribute to whether they find evolutionary theory applicable to their research.

\section{Discussion}

Consistent with our hypotheses, overall perceptions of the applicability of evolutionary theory within research programs housed in family studies and human development departments across the United States remain low. Variation in self-ratings of perceived applicability of evolutionary theory to extant lines of research was significantly impacted by participants' religious ideation, reported interest in and knowledge of evolution, and degree of meliorism, as measured by the MUSH scale.

Table 2 Regression analyses of participants' perceptions of evolutionary theory's applicability

\begin{tabular}{lccc}
\hline & $\begin{array}{l}\text { Standardized beta } \\
\text { coefficient }\end{array}$ & $t$ statistic & $p$ value \\
\hline Access to evolution & .199 & 2.20 & .03 \\
Religious ideation & .454 & 5.17 & $<.001$ \\
Interest/knowledge & .278 & 2.99 & .004 \\
MUSH & -.233 & -2.74 & .007 \\
\hline
\end{tabular}

An individual's access to evolution, religious ideation, degree of meliorism, and self-reported interest in and knowledge of evolution all uniquely contributed to whether participants reported evolutionary theory as applicable to their research interests; $R^{2}=.385(p<.001)$ 
The higher participants scored in meliorist attitudes (MUSH), the less likely they were to find evolution to be applicable to their areas of research. This is in line with our hypotheses, as well as with previous research, which has found that meliorists are less likely to favor theories that give any weight to biological factors ("nature" in the nature/nurture dichotomy), instead favoring theories that emphasis early childhood experiences and development ("nurture"; Charlesworth 1992). Although modern day evolutionary theory greatly emphasizes the bidirectional epigenetic effects that occur between an individual and her environment throughout all stages of development (King and Bjorklund 2010; King et al. 2010), it may be that meliorists' natural propensity to avoid evolutionarily based theories means that they are unfamiliar with or misinformed about the key tenets of evolution by natural selection.

Participants who rated themselves as more interested in and knowledgeable about evolutionary theory, as well as those who claimed to have high levels of access to evolution within their departments, were more likely to report higher levels of evolution's applicability to their research design. These findings are compelling because they suggest that if we educate people on the tenets of evolutionary theory, they will be able to find how evolution is applicable to their areas of research. Once people are interested in evolutionary theory, they are likely to seek it out, either by choosing university settings amenable to evolutionary teachings, or perhaps by creating their own evolution-friendly settings.

An unexpected finding was the relation between religious ideation and perceived applicability of evolutionary theory. Although those who rated themselves as more religious also rated themselves as less interested in and knowledgeable about evolutionary theory, they also were likely to rate it as applicable to their research areas. This surprising dichotomy could be a result of a social desirability bias; those who reported themselves as more religious perhaps wanting to appear open-minded to evolution's applicability, while still rating their knowledge level as low.

An interesting political correlation revealed that those who self-identified as extreme liberals also viewed evolutionary theory as less applicable. Although the range was skewed (no one identified as extreme conservative), the finding that extreme liberals don't find evolution applicable is not new (Richards 2008). Indeed, we had hypothesized that anyone who identified themselves at either end of the political spectrum would not report evolution as applicable to their area of research, each for different reasons (refer to "Political Impact" section in the Introduction). Because we had no participants that identified as extreme Republicans, the finding only emerged for extreme liberals, but if we had sampled from people who identified themselves on the polar end of the Republicans, we would have expected a similar finding to emerge. This finding confirms our hypothesis that political affiliation and attitudes toward evolution continue to be intertwined, sometimes acting as a barrier toward acceptance of evolutionary theory.

The fact that older participants reported more interest in and knowledge of evolutionary theory could speak to the fact that the older participants, mostly faculty, may have been exposed to more theoretical perspectives, and may be more knowledgeable about evolution by natural selection. Similarly, the fact that older people scored higher on attitudes of helpfulness could be a product of our sample and sampling method. It is not possible for us to tease apart whether this finding is due to age or to the status of the participants (e.g., faculty versus undergraduate). It could be that more advanced faculty members are more likely to have helpful attitudes, or it could also be that age was more of a factor than one's status as a faculty member, per se. Additionally, it is possible that this, too, could have been susceptible to a social desirability bias, especially being that attitudes of helpfulness were more common for older participants, but reports of actual helpfulness (i.e., instrumental helpfulness) actually decreased with age. Further studies will need to carefully measure these components to be able to make meaningful interpretations.

The fact that males reported more interest in and knowledge of evolution than females was not expected, but was not surprising given the multiple lines of research suggesting that males tend to be more interested in math and "hard" sciences relative to females (Eccles 1989). Evolutionary theory is unique among those frequently employed within family studies programs because it serves as a broad metatheoretical framework (Ketellar and Ellis 2000; Durrant and Ellis 2003), under which many mid-level theories, including those commonly used in family studies and human development (including feminism, attachment theory, and many others) operate. Because of its nature, it is firmly rooted in the physical sciences. Ironically, that is also what makes evolutionary theory so applicable to the social sciences. Although evolution may subsume other theories, it is not necessarily at odds with them, particularly those popular in family studies and human development departments. This is because evolution operates as an overarching theory. It spans various disciplines and has the power to bolster research by offering a broader perspective that takes into consideration multiple contexts in child development. Bronfenbrenner, a popular developmental theorist who proposed an Ecological Model of Child Development (1994), is commonly cited among researchers in family studies and human development departments. His model spans from the microsystem (individual level) through the macrosystem (cultural and societal influences on development); an evolutionary perspective is not at odds with, but 
broadens this perspective by considering all of these levels of development, as well as going beyond to the evolutionary level (looking at changes across the species' phylogeny). Because of evolution's universality, it can stand to inform and improve many other prominent family studies perspectives.

For example, researchers utilizing feminist perspectives could easily integrate and supplement their approach to scholarship by acknowledging that both perspectives hold similar values. Feminists stress the "importance of men and women to social life, the connectedness of structures and processes found in macro and micro settings" as do evolutionists, who emphasize the influence of ecology and social configurations on family and sexual structures between men and women (Fox and Murry 2000, p. 1160; Hrdy 1981). Additionally, both evolutionary theory and feminist perspectives acknowledge the reproductive control men place on women and how varying social structures may exacerbate or minimize the control (Fox and Murry 2000; Gowaty 1992; Hrdy 1981; Lancaster 1991); according to some, however, only evolutionary theory can provide answers to key family and development issues as to why these issues are present in society in the first place, such as female sexual subordination, jealousy, and spousal abuse (Wilson and Daly 1992), teenage pregnancy (Burton 1990; Ellis 2004), and why some men are better fathers than others (Geary 2000; Trivers 1972).

For example, Hrdy $(1981,2009)$ emphasizes that traditional "nuclear families" within evolutionary history were not the norm; instead, she states that evolution favored various configurations of family structures, such as multiple women caring for dependent offspring. Feminist perspectives, similar to evolutionary frameworks, value variation and seek to eliminate typologies of sex and family structure and embrace fluidity of roles (Fox and Murry 2000; Gowaty 1992). Typologies could hinder scientific insight, causing scholars to potentially miss configurations that are "naturally" occurring (Gowaty 1992). Incorporating an evolutionary approach to family and developmental studies emphasizes that variants of the family (and of individual development) are not aberrations but predictable responses to an environment in which the organism lives. The perspective leaves no room for judgments and value labels in analysis of family configurations. Instead, scholars investigate why the environment has activated certain adaptations, such as teenage child-bearing in certain groups (Geronimus 1996), and seek solutions that can alter environments in order to alleviate such problems.

By integrating evolutionary theory, feminist researchers would not only be supplementing their research, but adding a unique voice to evolutionary sciences where male researchers often dominate (Gowaty 1992; Hrdy 1981) and may present a new voice and focus on the experiences of women in society from an evolutionarily informed perspective.

\section{Training Programs and Pedagogical Shifts}

The fact that many people in family studies and human development departments do not find evolutionary theory applicable to their research is not surprising to these authors. Much resistance is still seen due to political affiliations, meliorist attitudes, and religious ideals. To overcome these areas of resistance, some simple suggestions can be made to help both students and faculty alike see how their theories of choice are not at odds with an evolutionary perspective and how proper training can help bridge the gaps in knowledge which often lead to misunderstanding about evolutionary theory and its applicability. We argue that incorporating an evolutionary perspective can link various disciplines and strengthen research programs.

Introducing an evolutionary perspective has the ability to reduce some of the bias that can occur within family studies and human development programs due to the problem of reflexivity. Reflexivity is when scholars acknowledge their personal experiences, intuition, and values while conducting research (Fox and Murry 2000). Many theoretical perspectives in the areas of family studies and human development emphasize reflexivity, so filtering "personal experiences and intuition" through a Darwinian lens could possibly correct and control for some of the bias in research, since metatheoretical parameters have already been established, thus producing more scientifically rigorous research designs with reduced methodological biases (Liesen 2008).

Implementing evolutionary theory into family studies curricula is not as daunting of a task as it may seem at first glance. Indeed, Wilson et al. (2009) have gone a long way toward meeting this goal by creating an Evolutionary Studies (EvoS) program at two universities, with the hopes that it can serve as a model for other universities, as well. EvoS has been designed to be a campus-wide seminar that both students and faculty are able to attend to discuss a variety of evolutionarily oriented themes spanning several disciplines (Wilson et al. 2009). The inception of the idea occurred because Wilson and colleagues noticed the growing gap between evolutionarily relevant scientific research being published and the dissemination of that information across graduate and undergraduate curricula. Wilson started the first EvoS program simply by gathering like-minded faculty who would be willing to take turns discussing their area of expertise in a biweekly meeting. Through this, faculty was able not only to interact with students, but with other faculty from different departments, as well. Undergraduates and graduates thrived from the 
open-ended discussions and often stayed late to converse amongst themselves as well as with the week's guest speaker. Over time, a positive feedback cycle ensued and the number of participants has since tripled in size (Wilson et al. 2009). Despite, and perhaps because of, its humble beginnings, this EvoS program can be used as a paragon for other university systems to mimic.

A carefully implemented course on evolution and its applications could prove highly beneficial for students and faculty affiliated with family studies and human development departments. Such a course could resolve many of the resistances that people often face by educating them about the nature of evolutionary theory and introducing them to potentially fruitful collaborative partnerships with people from across their university campus with whom they may never have otherwise had a chance to meet. By learning more about the tenets of evolutionary psychology (and more specifically about those of evolutionary developmental psychology), family studies faculty and students can realize the importance of the bidirectional epigenetic processes that occur between an organism and its environment (King et al. 2010; King and Bjorklund 2010).

The impact of such an integration would have farreaching effects. Indeed, evolutionary-based research can help provide a theoretically grounded basis upon which much public policy could be built. By understanding the ultimate causes of human behavior, researchers are able to provide a more compelling solution to problems such as teen pregnancy or gang violence, by understanding why such phenomena exist. By understanding that these socalled "risky" behaviors must have evolved to solve some adaptive problem faced by our ancestors over time, researchers are better able to think of ways to overcome these obstacles. Evolution offers much explanatory power and can be helpful when implementing public policy and prevention programs because it allows us as researchers to look deeper at the root cause of these problems, thus aiding us in solving the ultimate problem, rather than simply treating the proximate manifestation of it. Finally, by teaching those within family studies programs of the applicability of an evolutionary perspective to their research interests, we can appeal to their meliorist personalities by explaining that incorporating evolution into their research can actually better mankind by better addressing the age-old problems and research questions often addressed in family studies and human development departments.

\section{Summary}

Evolution is already a major unifying theory throughout the biological sciences and here we argue that it has much to offer the social sciences as well. Applying an evolutionary perspective to the study of families and human development can link these research programs with various disciplines and can, as a result, strengthen research designs by offering a more comprehensive view of human behavior. In this article, we have identified and addressed some of the key areas of resistance toward evolutionary theory within family studies and human development. Although much work is needed to continue incorporating evolutionary theory into research within family studies programs, an EvoS program that seeks to educate students and faculty of evolution's applicability may prove most useful in breaking down some of the traditional barriers that have been in place within family studies departments.

\section{Appendix}

Attitudes Toward Evolution

\section{Interest/Knowledge}

To what extent do you believe natural selection is continuing to act as a selective pressure within the human species?

If you wanted to incorporate the principals of natural selection and evolution into your research, how difficult would it be to do so with your current knowledge/ understanding?

\section{Perceived Applicability}

How relevant do you think evolution is to your specific (research) interests?

To what extent does evolutionary theory impact your work/studies?

\section{Religious Ideation}

To what extent do you agree with the following statement, "I feel evolution poses a threat to my religious beliefs?"

To what extent do you believe that religious beliefs affect your attitude toward evolutionary theory?

\section{Access to Evolution}

To what extent are cross-disciplinary and comparative methods of research encouraged by your department?

If you were interested in studying from an evolutionary perspective, how easy would it be to find mentorship within your department? 
Measure of Understanding, Support and Helpfulness (MUSH)

\section{Understanding}

I often have tender, concerned feelings for people less fortunate than me.

I am often quite touched by things that I see happen.

\section{Support}

Other people often come to me when they are in need of assistance/support/etc.

I don't care if I hurt people on the road to success.

\section{Attitudes of Helpfulness}

I have important skills I can pass along to others.

I frequently teach things to people.

\section{Instrumental Helpfulness}

I have assisted someone experiencing car trouble (changing a tire, calling a mechanic, pushing a stalled or stuck car, etc.). I have given someone directions.

\section{References}

Alcock J. Animal behavior: an evolutionary approach. 9th ed. Sunderland: Sinauer Associates, Inc.; 2009.

Auburn University. Auburn University enrollment statistics. 2010. Retreived from http://www.auburn.edu/student_info/bulletin/ enrollment_stats.pdf.

Barlow N. editor. The autobiography of Charles Darwin 1809-1882. 1958. Retrieved from http://darwin-online.org.uk/content/frameset? viewtype $=$ side \&itemID $=$ F1497\&pageseq $=1$.

Bishop BA, Anderson CW. Student conceptions of natural selection and its role in evolution. Journal of Research in Science Teaching. 1990;27:415-427.

Bjorklund DF. Why youth is not wasted on the young: immaturity in human development. Oxford: Blackwell; 2007.

Bjorklund DF, Green BL. The adaptive nature of cognitive immaturity. American Psychologist. 1992;46-54.

Bowlby J. Maternal care and mental health. New Jersey: Aronson; 1951.

Bowlby J. Separation: anxiety and anger. New York: Basic Books; 1973.

Bronfenbrenner U. Ecological models of human development. In: Gauvain, M. \& Cole, M. editors. International Encyclopedia of Education, vol. 3, 2nd. ed. Oxford: Elsevier. Reprinted in, Readings on the development of children, 2nd ed. NY: Freeman; 1994. (1993, p. 37-43).

Burton LM. Teenage childbearing as an alternative life-course strategy in multigenerational black families. Hum Nat. 1990;1:123-43.

Campbell A. The essential woman: Biophobia and the study of sex differences. In: Campbell A, editor. A mind of her own: the evolutionary psychology of women. Oxford, UK: Oxford University Press; 2002. p. 1-33.
Caruso DR, Mayer JD. A measure of emotional empathy for adolescents and adults. Unpublished manuscript. 1998.

Charlesworth WR. Darwin and developmental psychology: past and present. Dev Psychol. 1992;28:5-16.

College Board. College search. 2010. Retrieved from: http://college search.collegeboard.com/search/servlet/advsearchservlet?button Pressed $=$ next\&navigate $\mathrm{To}=9$.

D'Antonio WV, Hoge DR. The American experience of religious disestablishment and pluralism. Soc Compass. 2006;53:345-56.

Dahl RE. Adolescent brain development: A period of vulnerabilities and opportunities. In Ronald E Dahl and Linda Patia Spear (Eds.), Annals of the New York Academy of Sciences. 2004;1-22.

Darwin F, editor. The life and letters of Charles Darwin, volume II. 1887. Retrieved from http://darwin-online.org.uk/content/frame set?itemID=F1452.2\&viewtype=text\&pageseq $=1$.

Davis MH. A multidimensional approach to individual differences in empathy. JSAS Catalog Selected Doc Psychol. 1980;10:85.

Davis MH. Measuring individual differences in empathy: evidence for a multidimensional approach. J Pers. 1983;51:167-84.

DelGiudice M, Ellis BJ, Shirtcliff EA. The adaptive calibration model of stress responsivity. Neuroscience and biobehavioral reviews. 2010. (in press).

Downie J. Evolution in health and disease: the role of evolutionary biology in the medical curriculum. Bioscience education, 4, 3 . 2004. Retrieved from http://www.bioscience.heacademy.ac.uk/ journal/vol4/beej-4-3.pdf.

Downie JR, Barron NJ. Evolution and religion: attitudes of Scottish first year biology and medical students to the teaching of evolutionary biology. J Biol Educ. 2000;34:139-46.

Durrant R, Ellis BJ. Evolutionary psychology. In: Gallagher M, Nelson RJ, editors. Comprehensive handbook of psychology, vol. 3: biological psychology. New York: Wiley; 2003. p. 1-33.

Eccles JS. Bringing young women to math and science. In: Crawford M, Gentry M, editors. Sex and thought. New York: Springer; 1989. p. 36-58.

Ellis BJ. Timing of pubertal maturation in girls: an integrated life history approach. Psychol Bull. 2004;130:920-58.

Erickson RJ. Why emotion work matters: sex, gender, and the division of labor. J Marriage Fam. 2005;67:337-51.

Fox GL, Murry VM. Sex and families: feminist perspectives and family research. J Marriage Fam. 2000;62:1160-72.

Geary DC. Evolution and proximate expression of human paternal investment. Psychol Bull. 2000;126:55-77.

Geary DC, Bjorklund DF. Evolutionary developmental psychology. Child Dev. 2000;71:57-65.

Geher G, Gambacorta D. Evolution is not relevant to sex differences in humans because I want it that way! Evidence for the politicization of human evolutionary psychology. EvoS J J Evol Stud Consortium. 2010;2(1):32-47.

Geronimus AT. What teen mothers know. Human Nature. 1996;7:323-352.

Gowaty PA. Evolutionary biology and feminism. Hum Nat. 1992;3: 217-49.

Hagard P, Findlay S. Getting to Darwin: obstacles to accepting evolution by natural selection. Sci Educ. 2010;19:626-36.

Hagen EH. Controversial issues in evolutionary psychology. In: Buss DM, editor. The handbook of evolutionary psychology. Hoboken: John Wiley and Sons, Inc; 2005. p. 145-73.

Hrdy S. The woman that never evolved. Cambridge: Harvard University Press; 1981.

Hrdy SB. Mothers and others: the evolutionary origins of mutual understanding. Cambridge: Belknap; 2009.

Ketellar T, Ellis BJ. Are evolutionary explanations unfalsifiable? Evolutionary psychology and the lakatosian philosophy of science. Psychol Inq. 2000;11:1-21.

King AC, Bjorklund DF. Evolutionary developmental psychology. Psicothema. 2010;22:22-7. 
King AC, Schlomer GL, Ellis BJ. Evolutionary developmental psychology. In: Ramachandran VS, editor. To appear, Encyclopedia of human behavior, 2. 2010. (in press).

Lancaster JB. A feminist and evolutionary biologist looks at women. Am J Phys Anthropol. 1991;34:1-11.

Liesen LT. The evolution of sexed political behavior: contributions from feminists. Sex Roles. 2008;59:476-81.

Miller JD, Scott EC, Okamoto S. Public acceptance of evolution. Science. 2006;313:765-6.

Perry G, Mace R. The lack of acceptance of evolutionary approaches to human behavior. J Evol Psychol. 2010;8:105-25.

Piaget J. The child's conception of the world. New York: Harcourt, Brace \& World. 1930. (Original work published 1926).

Richards RA. Philosophical challenges in teaching evolution. Evol Educ Outreach. 2008;1:158-64.

Scott EC. Antievolution and creationism in the United States. Annu Rev Anthropol. 1997;26:263-89.

Shtulman A. Qualitative differences between naïve and scientific theories of evolution. Cogn Psychol. 2006;52:170-94.

Sigelman CK, Rider EA. Life-span human development. 6th ed. Belmont, CA: Wadsworth Cengage Learning; 2009.

Sikkink L. Teaching evolution as a cultural anthropologist: student perceptions of evolution at Western State College. Gen Anthropol. 2009;16(2):1-10.
Stapel DA, Koomen W. Competition, Cooperation, and the Effects of Others on Me. Journal of Personality And Social Psychology. 2005;88:1029-1038

Trani R. I won't teach evolution: it's against my religion. And now for the rest of the story. Am Biol Teach. 2004;66:419 27.

Trivers RL. Parental investment and sexual selection. In: Campbell B, editor. Sexual selection and the descent of man. London: Heinemann; 1972. p. 136-79.

Tybur JM, Miller GF, Gangestad SW. Testing the controversy: an empirical examination of adaptationists' attitudes toward politics and science. Human Nature; 2007. p. 313-328.

Wilson DS. Evolution for everyone: how Darwin's theory can change the way we think about our lives. New York: Bantam Dell; 2007.

Wilson M, Daly M. The man who mistook his wife for a chattel. In: Barkow JH, Cosmides L, Tooby J, editors. The adapted mind: evolutionary psychology and the generation of culture. New York: Oxford University Press; 1992. p. 289-322.

Wilson DS, Geher G, Waldo J. EvoS: completing the evolutionary synthesis in higher education. EvoS J J Evol Stud Consortium. 2009;1:3-10.

Wright R. Feminists, meet Mr. Darwin. New Republic, 28 November, 1994.p. 34-36. 